\title{
Adults with attention-deficit/hyperactivity disorder - a brain magnetic resonance spectroscopy study
}

\section{Margaretha Dramsdahl ${ }^{1,2}{ }^{*}$, Lars Ersland ${ }^{3,4}$, Kerstin J. Plessen ${ }^{5,6,7}$, Jan Haavik ${ }^{1,78}$, Kenneth Hugdahl ${ }^{1,79}$ and Karsten Specht ${ }^{3,9}$}

1 Division of Psychiatry, Haukeland University Hospital, Bergen, Norway

${ }^{2}$ Department of Clinical Medicine, University of Bergen, Bergen, Norway

${ }^{3}$ Department of Clinical Engineering, Haukeland University Hospital, Bergen, Norway

${ }^{4}$ Section for Radiology, Department of Surgical Sciences, University of Bergen, Bergen, Norway

${ }^{5}$ Center for Child and Adolescent Psychiatry at Bispebjerg, Copenhagen, Denmark

${ }^{6}$ Institute for Neurology, Psychiatry, and Sensory Sciences, University of Copenhagen, Copenhagen, Denmark

${ }^{7}$ K.G. Jebsen Centre for Research on Neuropsychiatric Disorders, University of Bergen, Bergen, Norway

${ }^{8}$ Department of Biomedicine, University of Bergen, Bergen, Norway

${ }^{9}$ Department of Biological and Medical Psychology, University of Bergen, Bergen, Norway

\section{Edited by:}

Ziad Nahas, Medical University of

South Carolina, USA

Reviewed by:

Jarred Younger, Stanford University

School of Medicine, USA

Darin Dougherty, Massachusetts

General Hospital, USA

*Correspondence:

Margaretha Dramsdahl, Division of Psychiatry, Haukeland University

Hospital, Jonas Lies vei 65, N-5021

Bergen, Norway.

e-mail: margaretha.dramsdahl@helsebergen.no
Background: Impaired cognitive control in individuals with attention-deficit/hyperactivity disorder (ADHD) may be related to a prefrontal cortical glutamatergic deficit. We assessed the glutamate level in the left and the right midfrontal region including the anterior cingulate cortex in adults with ADHD and healthy controls. Methods: Twenty-nine adults with ADHD and 38 healthy controls were included. We used Proton Magnetic Resonance Imaging with single voxel point-resolved spectroscopy to measure the ratio of glutamate to creatine $(\mathrm{Glu} / \mathrm{Cre})$ in the left and the right midfrontal region in the two groups. Results: The ADHD group showed a significant reduction of Glu/Cre in the left midfrontal region compared to the controls. Conclusion: The reduction of Glu/Cre in the left midfrontal region in the ADHD group may reflect a glutamatergic deficit in prefrontal neuronal circuitry in adults with $A D H D$, resulting in problems with cognitive control.

Keywords: ADHD, MR spectroscopy, MRS, glutamate, Glu/Cre, cognitive control, cortex cinguli anterior, ACC

\section{INTRODUCTION}

Attention-deficit/hyperactivity disorder (ADHD) is a neurodevelopmental disorder with three distinct clinical subtypes; the inattentive, the hyperactive/impulsive, and the combined type. The pooled prevalence of children and adolescents with ADHD worldwide is estimated to $5.3 \%$ (Polanczyk et al., 2007). Approximately $65 \%$ of affected children show persistent symptoms with functional impairment into adulthood (Faraone et al., 2006), whereas some children experience an improvement or even complete elimination of symptoms during adolescence, which may be explained by a delay and later catch-up in cortical maturation (Shaw et al., 2007). Adults with persisting ADHD thus may represent a subgroup with symptoms caused by other neurobiological underpinnings than a mere delay of cortical development.

Although ADHD is regarded as a neuropsychologically heterogeneous disorder (Willcutt, 2005; Doyle, 2006; Sonuga-Barke et al., 2010), deficits in cognitive control are considered key impairments in this disorder. A cognitive control process presumably taps the executive control network (Hugdahl et al., 2009), which is one of the three networks described in the attentional networks model (Fan et al., 2005, 2009). The anterior cingulate cortex (ACC) is part of the executive control network (Posner and Rothbart, 2007) and its function is essential for the exertion of cognitive control (Bush et al., 2000; Carter and Van Veen, 2007). Studies using functional neuroimaging (Bush et al., 2005) suggest that a dysfunction in the dorsal ACC plays a role in the pathophysiology of ADHD.
The ACC has a high density of glutamate receptors (Vogt, 2009), and glutamate may be an important metabolite for cognitive functions (O'neill and Dix, 2007). Glutamatergic neurotransmission may prove a key target in the treatment of several psychiatric disorders (Javitt, 2004), and growing research on the psychopharmacology of glutamate receptor agonists and antagonists documents an increasing interest for its therapeutic use in psychiatry (Parsons et al., 2005; Krystal et al., 2010; Lesage and Steckler, 2010). A recent study (Ludolph et al., 2010) highlights the role of glutamate in ADHD by demonstrating that the norepinephrine reuptake inhibitor atomoxetine, which is effective against ADHD symptoms, is also an NMDA receptor antagonist.

Magnetic resonance spectroscopy (MRS) is a non-invasive method to measure metabolites in the brain (Graaf, 2007). Earlier MRS studies of persons with ADHD have focused on metabolites like choline compounds, $N$-acetyl aspartate (NAA), glutamate (Glu), and glutamine (Gln; Perlov et al., 2009). A synthesis of Glu and Gln (Glx) has often been used, because the separation of Glu and Gln proves difficult at lower field strengths. The separation of Glu from Gln is, however, possible at field strengths as low as $2 \mathrm{~T}$ if using a short echo time (TE) and the linear combination of model (LCModel; Provencher, 1993, 2001). The concentration of total creatine (Cre) is relatively constant, which is why this metabolite has often been used as an internal concentration reference (Graaf, 2007; Dager et al., 2008). 
A recent meta-analysis including 16 MRS studies of participants with ADHD concluded with altered Glx/Cre, NAA/Cre, and Choline/Cre ratios (Perlov et al., 2009) in patients relative to controls. However, only three of these studies included adults. To our knowledge, a total of seven MRS studies of adults with ADHD have been published (Hesslinger et al., 2001; Perlov et al., 2007, 2010; Colla et al., 2008; Kronenberg et al., 2008; Ferreira et al., 2009; Rusch et al., 2010), of which the ACC has been examined specifically in four studies. Although a significantly reduced Glx/Cre ratio in ACC was reported in one study (Perlov et al., 2007), other findings have been inconsistent across studies, possibly explained by heterogeneity of the sample and different spectroscopic methodologies.

In this MRS study we aimed at focusing on the midfrontal region due to the assumed importance of the ACC for cognitive control functions, which in turn are central in the pathophysiology of ADHD. Glutamate is essential in neurotransmission in the ACC and may prove a key metabolite in cognitive functions, and we thus hypothesized that adults with ADHD would show a reduction of the glutamate level in the midfrontal region compared with the controls.

\section{MATERIALS AND METHODS PARTICIPANTS}

The sample of 29 participants with ADHD and 38 healthy controls was recruited from the Norwegian ADHD-project in Bergen. The ADHD group consisted of 15 men and 14 women with mean age 32.9 years ( $S D=7.1$, age range $21-48$ years) and mean Wechsler Abbreviated Scale of Intelligence (WASI) IQ 110.6 ( $\mathrm{SD}=14.3$, IQ range 78-128). The control group consisted of 15 men and 23 women with mean age 29.8 years $(S D=6.5$, age range $21-$ 41 years) and mean WASI-IQ 116.3 ( $\mathrm{SD}=9.4$, IQ range 96-136). The groups did not differ significantly neither in their composition of $\operatorname{sex}\left(\chi^{2}=1.00 ; \mathrm{df}=1 ; p=0.32\right)$, nor with respect of means of age $[t(65)=1.84 ; p=0.07]$ or means of IQ $[t(65)=-1.97$; $p=0.053]$.

All patients had been diagnosed according to ICD-10 or DSMIV criteria for hyperkinetic disorder/ADHD by a psychiatrist or psychologist before the inclusion in the Norwegian ADHD-project in Bergen. Controls were randomly selected from the comparison group in the Norwegian ADHD-project in Bergen (Halmoy et al., 2009), recruited from the database of the Medical Birth Registry of Norway. Details concerning the recruitment procedure are described in recent publications by the Bergen group (Johansson et al., 2008; Halleland et al., 2009; Halmoy et al., 2009). All participants in both groups were interviewed with the ADHD module of K-SADS (Kaufman et al., 1997) adjusted to adults, administered by an experienced psychiatrist (Margaretha Dramsdahl). Based on symptoms reported in childhood, the participants were categorized into the following subgroups: seven with inattentive type, three with hyperactive/impulsive type and 19 participants with combined type. According to the present symptoms, however, nine participants had an inattentive type, one had symptoms of the hyperactive/impulsive type and 19 participants had a combined type. The Adult ADHD Self-Report Scale (ASRS-18; Kessler et al., 2005) was used to determine current ADHD symptoms in both groups. It consists of two subscales, one scale measuring inattentive symptoms, the other scale measuring hyperactive/impulsive symptoms.

The ADHD group included both medication naïve as well as medicated participants. The 16 patients medicated with stimulants $(n=15)$ or atomoxetine $(n=1)$ were instructed to withhold medication $48 \mathrm{~h}$ prior to testing to reduce the possible influence of medication. Nine participants followed this instruction, whereas five reduced the dosage during the last $48 \mathrm{~h}$ (including the sole participant on atomoxetine), and two participants continued their ordinary medication. Thirteen of the participants in the ADHD group had not used stimulants or atomoxetine during the past 6 months.

Participants with ADHD consisted of 23 right-handed and 6 left-handed participants, whereas 33 right-handed and 5 lefthanded controls were included. Handedness was determined by the hand that the subject preferred to draw and write with.

Exclusion criteria for both groups were current severe psychiatric axis I disorder or substance abuse, epilepsy, or other neurological or physical disease with cognitive impairment. Participants with a lifetime history of developmental delay, premature birth before 34 weeks of gestational age, or IQ below 70 were neither included. To ensure as representative ADHD sample as possible, we included participants with current mild psychiatric comorbidity (anxiety disorders and mild depressive symptoms). Eleven of the ADHD participants had diagnosis of an anxiety disorder (panic disorder, agoraphobia, social phobia, and/or specific phobia), two had a depressive disorder or dysthymia, and three ADHD participants had diagnosis of both anxiety and depressive disorder. No participant, however, reported ongoing, severe symptoms at the time for the MR scanning. Further exclusion criteria for the controls were lifetime history of ADHD, current ADHD symptoms (score $>36$ on ASRS-18, or $>20$ on one of the two subscales), or first-degree relatives (parents, children, siblings) with ADHD. Three of the controls had diagnosed specific phobia, but none had ongoing symptoms at the time of scanning.

Written informed consent was obtained from all participants after receiving detailed information about the procedure. The study was approved by the Norwegian Regional Medical Research Ethics Committee West IRB \#3 (FWA00009490, IRB00001872).

\section{MR SPECTROSCOPY}

${ }^{1} \mathrm{H}-\mathrm{MR}$ scanning was performed with a 3.0-T GE Signa HDx scanner, using an eight-channel head coil. Single voxel point-resolved spectroscopy (PROBE-PRESS) was used with the following parameters: TE $=35 \mathrm{~ms}, \mathrm{TR}=1500 \mathrm{~ms}$. Line-width was less than $8 \mathrm{~Hz}$ and water suppression level at least $94 \%$.

A $T_{1}$-weighted image using a 3D Fast Spoiled Gradient Recall sequence $(\mathrm{TE}=14 \mathrm{~ms}, \mathrm{TR}=400 \mathrm{~ms}, \mathrm{TI}=500 \mathrm{~ms}$; scan matrix: $256 \times 256$; field of view of $256 \mathrm{~mm} \times 256 \mathrm{~mm}, 188$ sagittal slices of $1 \mathrm{~mm}$ thickness) was acquired to position the slices parallel to the line connecting the lowest edge of the splenium and the rostrum of the CC. In addition to the $T_{1}$-weighted image an axial $T_{2}$-weighted image was acquired prior to the proton MRS imaging sequences. The $T_{2}$-weighted image was used as reference for cerebrospinal fluid (CSF) within the area of interest to avoid CSF contamination of the MRS voxel. 
Voxel size was $20 \mathrm{~mm} \times 20 \mathrm{~mm} \times 20 \mathrm{~mm}$ localized in the left and the right midfrontal region including the dorsal ACC. The position of the MRS voxel was parallel to the CC, midway between the upper part of the mid-body of the CC, and the most anterior part of the genu, close against the edge of the white matter in the CC (Figure 1). Scanning was performed with the MRS voxel localized first in the left and then in the right midfrontal region.

\section{DATA ANALYSIS}

The ratio of Glu to Cre were estimated by LCModel software version 6.2-1A using a simulated basis-set for a TE of $35 \mathrm{~ms}$, delivered by Provencher (2011). LCModel automatically quantifies in vivo spectra, avoiding analyses of individual peaks or use of any subjective influenced model. Estimated SD (Cramér-Rao lower bounds) below $20 \%$ were accepted, which is a rough criterion for estimates of acceptable reliability (Provencher, 2011).

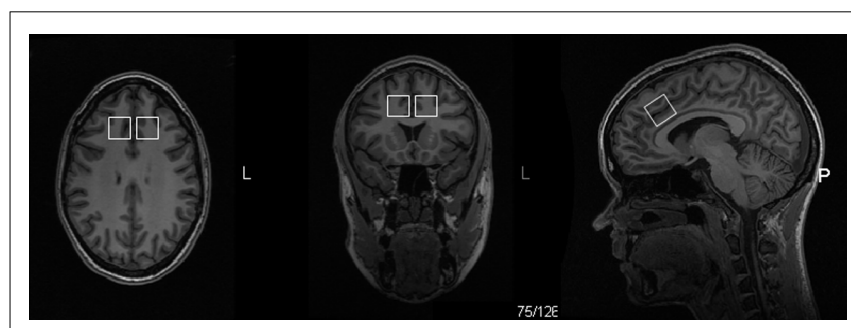

FIGURE 1 | The position of the $20-\mathrm{mm} \times 20-\mathrm{mm} \times 20-\mathrm{mm}$ voxel in the midfrontal region.
All statistical analyses were made by general linear model (GLM) using the Statistica 8 software (http://www.statsoft.com/). Group comparisons were made between the ADHD and control group and between the left and right side in a multivariate analysis of variance (MANOVA) including Glu/Cre left and Glu/Cre right as dependent variables and group as categorical variable. In order to control for any effect of covariates, the data were reanalyzed with multivariate analysis of covariance (MANCOVA) including Glu/Cre left and Glu/Cre right as dependent factors, group, sex, and handedness as categorical predictors, and age and IQ as continuous predictors. Since none of the interactions were significant, we removed the interaction terms before re-running the analysis twice with Glu/Cre left and Glu/Cre right, respectively, as dependent variables, group as categorical predictor, and sex, handedness, age, and IQ as covariates. Medication and comorbidity were not included as covariates in the GLM analyses, since these variables had implications mainly for the ADHD group, and some of the subgroups would be very small or even give empty cells in the statistical design. Thus, to investigate the effect of comorbidity and medication we did independent $t$-tests of the ADHD group with Glu/Cre ratio left side as dependent variable and comorbidity and medication, respectively, as grouping variables. As a last analysis we correlated the value of Glu/Cre in the left midfrontal region and scores of the two ASRS subscales to explore a possible association.

\section{RESULTS}

All spectra of the 67 included participants were of good quality (see Figure 2 for a representative spectrum).

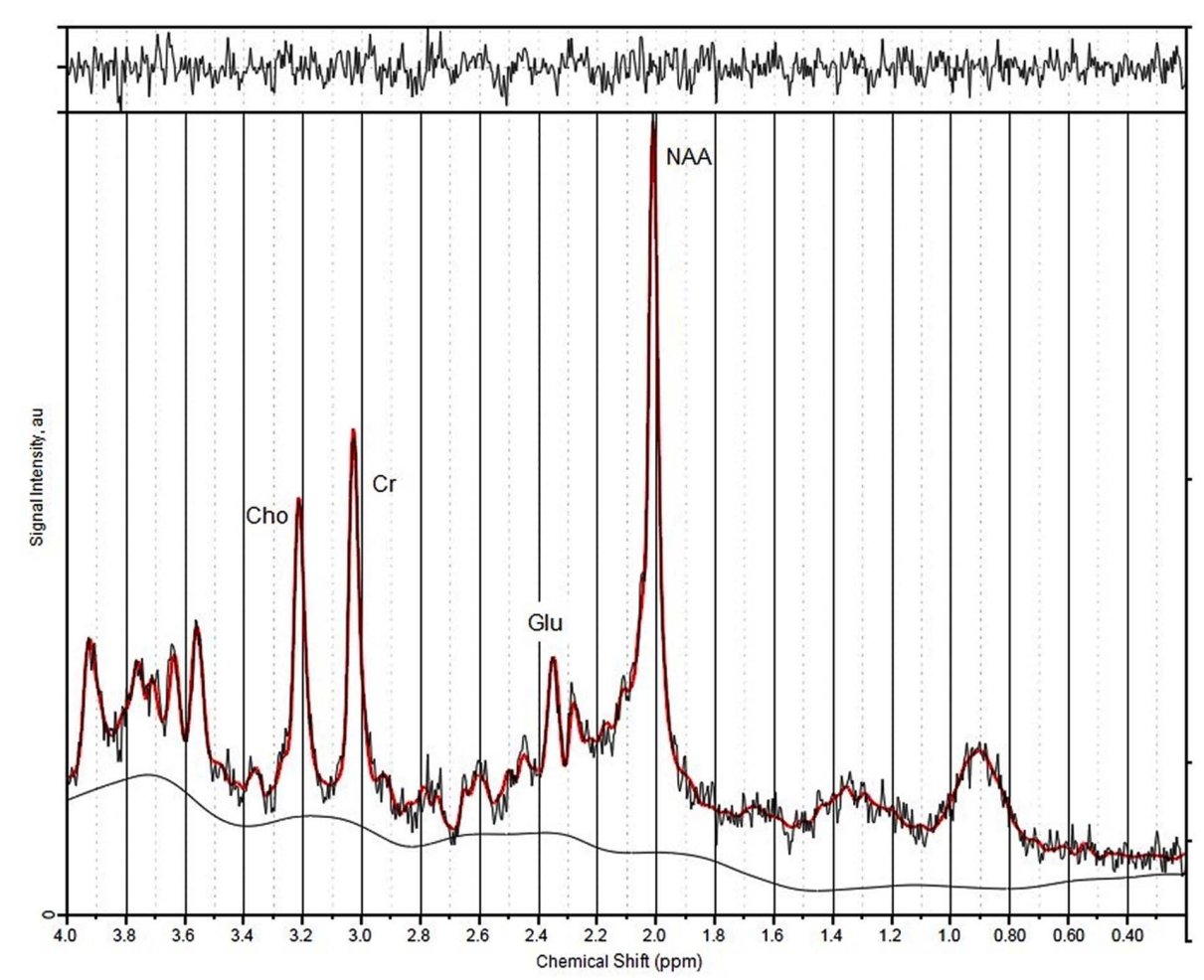

FIGURE 2 |A representative spectrum indicating position of peaks and calculation of signal-to-noise ratios. 
The MANOVA including Glu/Cre left and Glu/Cre right as dependent variables and group as categorical variable revealed significant main effects of group and of side (Table 1; Figure 3 ). The mean Glu/Cre ratio was reduced in the ADHD group compared to the control group and the difference was only significant in the left midfrontal area. The mean Glu/Cre ratio was significantly lower in left midfrontal region compared to right midfrontal region in both groups. The MANCOVA including Glu/Cre left and Glu/Cre right as dependent factors, group, sex, and handedness as categorical predictors, and age and IQ as continuous predictors, revealed a significant main effect of group, but no longer any significant side effect (Table 2). Age and IQ had each a significant main effect, but, more importantly, no interactions between the factors became significant.

The ANCOVAs with Glu/Cre left and Glu/Cre right, respectively, as dependent variables, group as categorical predictor, and sex, handedness, age, and IQ as covariates confirmed a main effect of group at the left side, but not at the right (see Table A2 in Appendix).

In order to further elaborate the significant group effect in the left midfrontal area, detected by the MANOVA, follow up statistics were performed for this region, only. The $t$-test of the ADHD group with Glu/Cre ratio left side as dependent variable and comorbidity as grouping variable revealed significant

Table 1 | Main and interaction effects of general linear model including glutamate/creatine ratios at left and right side as dependent variables and group (ADHD, control) as categorical predictors.

\begin{tabular}{llllll}
\hline & SS & df & MS & $\boldsymbol{F}$ & $\boldsymbol{p}$ \\
\hline Group & 0.269 & 1 & 0.269 & 8.34 & $0.005^{*}$ \\
Side & 0.288 & 1 & 0.288 & 13.48 & $0.000^{*}$ \\
Side $\times$ group & 0.009 & 1 & 0.009 & 0.43 & 0.513
\end{tabular}

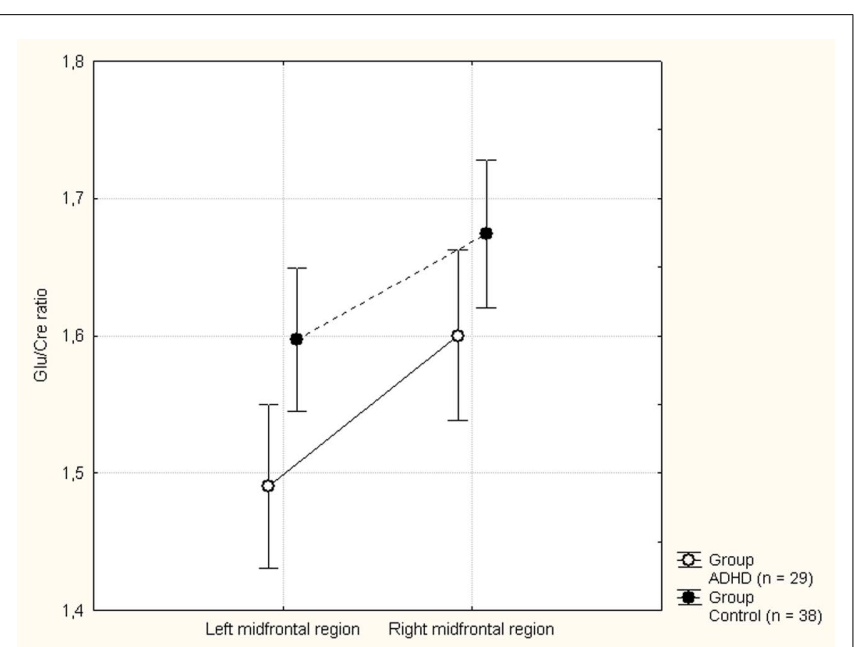

FIGURE 3 | Mean glutamate to creatine (Glu/Cre) ratio in the left and right midfrontal region in the attention-deficit/hyperactivity disorder (ADHD) and control groups. Vertical bars denotes $95 \%$ confidence intervals. lower Glu/Cre value in the ADHD group without comorbidity compared to the ADHD group with comorbidity (see Table A1 in Appendix). The $t$-test of the ADHD group including medication as grouping variable showed no significant difference in Glu/Cre ratio at left side between the medicated and non-medicated ADHD participants (see Table A1 in Appendix).

The correlation between the symptoms of severity (ASRS scores) and the value of Glu/Cre in the left midfrontal region of the ADHD participants revealed no significant correlation. When including the controls and thus increasing the statistical power, a significant negative correlation between inattentive symptoms and Glu/Cre level was revealed ( $r=-0.274, p=0.025)$. There was no significant correlation between the hyperactive/impulsive scores and the level of Glu/Cre in left midfrontal region $(r=-0.107$, $p=0.39$ ).

\section{DISCUSSION}

The main finding of a reduced ratio of Glu/Cre in the left midfrontal region in participants with ADHD supports the hypothesis of ADHD as a hypoglutamatergic condition (Carlsson, 2001). Glutamate is an important neurotransmitter in cognitive processes (Van Wageningen et al., 2009, 2010) and seems to have a central role in neurotransmission in the ACC (Bozkurt et al., 2005; Yang et al., 2006). The dorsal ACC, in turn, plays a crucial role in the exertion of cognitive control (Bush et al., 2000; Carter and Van Veen, 2007), and a glutamatergic deficit in the midfrontal region including the dorsal ACC, may contribute to the impaired cognitive control in persons with ADHD.

The hypothesis that a dysregulation of catecholaminergic neurotransmission contributes to the development of symptoms typical for ADHD has been supported from different research areas, notably from pharmacological studies of psychostimulants (Staller and Faraone, 2007; Genro et al., 2010). The exact modes of action of human ADHD-medication, however, are still unknown (Solanto, 1998; Challman and Lipsky, 2000; Cornforth et al., 2010). Although changes in dopamine or norepinephrine levels may primarily mediate the effect of psychostimulants, the putative monoamine dysfunction in ADHD may also derive from an impaired glutamatergic transmission (Carlsson, 2001).

Our results partially replicate and extend previous studies of brain glutamate levels in persons with ADHD, but comparisons between studies may be difficult because of methodological and/or

Table 2 | Main effects of general linear model including glutamate/creatine ratios at left and right side as dependent variables, group (ADHD, control), sex (man, woman), and handedness (left, right) as categorical predictors, and age and $I Q$ as continuous predictors.

\begin{tabular}{llllll}
\hline & SS & df & MS & $\boldsymbol{F}$ & $\boldsymbol{p}$ \\
\hline Group & 0.108 & 1 & 0.108 & 4.484 & $0.039^{*}$ \\
Side & 0.005 & 1 & 0.005 & 0.246 & 0.622 \\
Sex & 0.009 & 1 & 0.009 & 0.358 & 0.552 \\
Age & 0.175 & 1 & 0.175 & 7.264 & $0.009^{*}$ \\
IQ & 0.219 & 1 & 0.219 & 9.097 & $0.004^{*}$ \\
Handedness & 0.074 & 1 & 0.074 & 3.084 & 0.084
\end{tabular}


positional differences. One study concluding with significantly reduced Glx/Cre in the right ACC (Perlov et al., 2007) used multi-voxel chemical shift imaging (CSI) instead of single voxel spectroscopy. A recent single voxel MRS study reported increased glutamate concentration in the left ACC (Rusch et al., 2010), with the voxel of measurement positioned in the rostral part of ACC, anterior to the genu of the CC, and not in the dorsal, "cognitive" part. Furthermore, women were only included when ADHD was comorbid with a borderline personality disorder, making it difficult to draw conclusions about the specific impact of ADHD.

In addition to the diagnostic effect, we also revealed a significant main effect of side with reduced Glu/Cre in the left midfrontal area. A difference in Glu/Cre value between the left and the right side may indicate a lateralization of the frontal region including the dorsal part of the ACC. Reports of morphological differences between left and right midfrontal regions support this hypothesis, with the paracingulate sulcus more commonly found pronounced in the left compared to the right hemisphere (Huster et al., 2007; Fornito et al., 2008). The significant difference between the Glu/Cre in left and right midfrontal region disappeared, however, after correction for the covariates sex, handedness, age, and IQ (see Table 2).

The re-analysis showed a significant main effect of age. This finding is in accordance with earlier report of a slight decrease of Glu concentration in the ACC with increasing age (Schubert et al., 2004).

The exploratory finding of a significant negative correlation between inattentive symptoms and Glu/Cre level may support the presumption of glutamate in the midfrontal region as an important factor of cognitive control.

This study has several limitations. First, our sample is small with seven predictive variables (group, sex, handedness, age, IQ, medication, and comorbidity), and replication studies are thus necessary. We here present a representative ADHD sample, which increased the numbers of variables and possible confounding factors. The mean IQ value was lower in the ADHD group compared to the control group, but not significantly different. Cognitive difficulties in neurodevelopmental disorders like ADHD are, however, of such pervasive nature that matching fully for IQ is likely to reduce the representativeness of the ADHD group (Dennis et al., 2009). Likewise, any correction for comorbidity would result in a non-representative ADHD group. The significant lower Glu/Cre value in the ADHD group without comorbidity compared to the ADHD group with comorbidity support the presumption that

\section{REFERENCES}

Bozkurt, A., Zilles, K., Schleicher, A., Kamper, L., Arigita, E. S., Uylings, H. B., and Kotter, R. (2005). Distributions of transmitter receptors in the macaque cingulate cortex. Neuroimage 25, 219-229.

Bush, G., Luu, P., and Posner, M. I. (2000). Cognitive and emotional influences in anterior cingulate cortex. Trends Cogn. Sci. (Regul. Ed.) 4, 215-222.

Bush, G., Valera, E. M., and Seidman, L. J. (2005). Functional neuroimaging of attention-deficit/hyperactivity disorder: a review and suggested future directions. Biol. Psychiatry 57, 1273-1284.

Capizzano, A. A., Jorge, R. E., Acion, L. C., and Robinson, R. G. (2007). In vivo proton magnetic resonance spectroscopy in patients with mood disorders: a technically oriented review. J. Magn. Reson. Imaging 26, 1378-1389.

Carlsson, M. L. (2001). On the for the antithetical phenomenology role of prefrontal cortex glutamate

comorbidity cannot explain the main finding of reduced Glu/Cre ratio at left side in the ADHD group.

Second, the participants were on different medication regimes, and even if medication did not seem to have any significant influence in our study (see Table A1 in Appendix), it may have an influence on the neurochemistry and the neuronal activity. Inclusion of only medication naïve participants would be a way to eliminate a possible confounding effect of medication.

Third, changes in the Glu/Cre ratio may be a result of changes in the concentration of Cre. As an internal reference the concentration of Cre is supposed to be constant, and no changes have been reported with age, at least not before the age of 60 years (Saunders et al., 1999). The concentration of Cre, however, may vary in pathological conditions, such as mood disorders (Capizzano et al., 2007), brain tumors (Yerli et al., 2007), or ischemia (Karaszewski et al., 2010), and even small changes in the Cre value may influence the ratio of Glu to Cre. However, we analyzed the Glu/Cre ratio, because the ratio is less sensitive to relaxation and partial volume effects than the absolute concentrations of metabolites (Provencher, 2011). Unknown units of the absolute concentrations were another reason for using the ratios.

A last limitation is the possible confounding factors of offsets of the chemical shifts, as well as different distribution of CSF and gray and white matter in the voxels. We consider, however, the voxel size large enough to minimize these effects, but cannot eliminate a contribution of these factors to the differences between the sides, as well as the groups.

In conclusion, our results reflect a hypoglutamatergic condition in the midfrontal regions of adults with ADHD, which may cause impaired cognitive control and a dysfunctional top-down regulation. More studies mapping the glutamatergic pathways and their interaction with other transmitters in persons with ADHD would help to further reveal the underlying neurobiology of the disorder.

\section{ACKNOWLEDGMENTS}

We would like to thank Roger Barndon, Turid Randa, and Eva Øksnes for their contributions to the study, and Rolf Gjestad for his statistical support. The research was supported by grants from Division of Psychiatry, Haukeland University Hospital, The Research Council of Norway, Western Norway Regional Health Authority, and the Norwegian Research Network for AD/HD, Tourette Syndrome, and Narcolepsy. None of the authors report financial relationships with commercial interests.

of obsessive compulsive disorder and attention deficit hyperactivity disorder. Prog. Neuropsychopharmacol. Biol. Psychiatry 25, 5-26.

Carter, C. S., and Van Veen, V. (2007). Anterior cingulate cortex and conflict detection: an update of theory and data. Cogn. Affect. Behav. Neurosci. 7, 367-379.

Challman, T. D., and Lipsky, J. J. (2000). Methylphenidate: its pharmacology and uses. Mayo Clin. Proc. 75, 711-721.
Colla, M., Ende, G., Alm, B., Deuschle, M., Heuser, I., and Kronenberg, G. (2008). Cognitive MR spectroscopy of anterior cingulate cortex in ADHD: elevated choline signal correlates with slowed hit reaction times. J. Psychiatr. Res. 42, 587-595.

Cornforth, C., Sonuga-Barke, E., and Coghill, D. (2010). Stimulant drug effects on attention deficit/hyperactivity disorder: a review of the effects of age and sex of patients. Curr. Pharm. Des. 16, 2424-2433. 
Dager, S. R., Corrigan, N. M., Richards, T. L., and Posse, S. (2008). Research applications of magnetic resonance spectroscopy to investigate psychiatric disorders. Top. Magn. Reson. Imaging 19, 81-96.

Dennis, M., Francis, D. J., Cirino, P. T., Schachar, R., Barnes, M. A., and Fletcher, J. M. (2009). Why IQ is not a covariate in cognitive studies of neurodevelopmental disorders. J. Int. Neuropsychol. Soc. 15, 331-343.

Doyle, A. E. (2006). Executive functions in attention-deficit/hyperactivity disorder. J. Clin. Psychiatry 67(Suppl. 8), 21-26.

Fan, J., Gu, X., Guise, K. G., Liu, X., Fossella, J., Wang, H., and Posner, M. I. (2009). Testing the behavioral interaction and integration of attentional networks. Brain Cogn. 70, 209-220.

Fan, J., Mccandliss, B. D., Fossella, J., Flombaum, J. I., and Posner, M. I. (2005). The activation of attentional networks. Neuroimage 26, 471-479.

Faraone, S. V., Biederman, J., and Mick, E. (2006). The age-dependent decline of attention deficit hyperactivity disorder: a meta-analysis of follow-up studies. Psychol. Med. 36, 159-165.

Ferreira, P. E., Palmini, A., Bau, C. H., Grevet, E. H., Hoefel, J. R., Rohde, L. A., Anes, M., Ferreira, E. E., and Belmonte-DeAbreu, P. (2009). Differentiating attention-deficit/hyperactivity disorder inattentive and combined types: a (1)H-magnetic resonance spectroscopy study of frontostriato-thalamic regions. J. Neural Transm. 116, 623-629.

Fornito, A., Wood, S. J., Whittle, S., Fuller, J., Adamson, C., Saling, M. M., Velakoulis, D., Pantelis, C., and Yucel, M. (2008). Variability of the paracingulate sulcus and morphometry of the medial frontal cortex: associations with cortical thickness, surface area, volume, and sulcal depth. Hum. Brain Mapp. 29, 222-236.

Genro, J. P., Kieling, C., Rohde, L. A., and Hutz, M. H. (2010). Attentiondeficit/hyperactivity disorder and the dopaminergic hypotheses. Expert Rev. Neurother. 10, 587-601.

Graaf, R. A. D. (2007). In vivo NMR Spectroscopy: Principles and Techniques. Chichester: Wiley.

Halleland, H., Lundervold, A. J., Halmoy, A., Haavik, J., and Johansson, S. (2009). Association between catechol O-methyltransferase (COMT) haplotypes and severity of hyperactivity symptoms in adults. Am.J. Med. Genet. B Neuropsychiatr. Genet. 150B, 403-410.

Halmoy, A., Fasmer, O. B., Gillberg, C., and Haavik, J. (2009). Occupational outcome in adult
ADHD: impact of symptom profile, comorbid psychiatric problems, and treatment: a cross-sectional study of 414 clinically diagnosed adult ADHD patients. J. Atten. Disord. 13, 175-187.

Hesslinger, B., Thiel, T., Tebartz Van Elst, L., Hennig, J., and Ebert, D. (2001). Attention-deficit disorder in adults with or without hyperactivity: where is the difference? A study in humans using short echo (1)H-magnetic resonance spectroscopy. Neurosci. Lett. 304, 117-119.

Hugdahl, K., Westerhausen, R., Alho, K., Medvedev, S., Laine, M., and Hamalainen, H. (2009). Attention and cognitive control: unfolding the dichotic listening story. Scand. J. Psychol. 50, 11-22.

Huster, R. J., Westerhausen, R., Kreuder, F., Schweiger, E., and Wittling, W. (2007). Morphologic asymmetry of the human anterior cingulate cortex. Neuroimage 34, 888-895.

Javitt, D. C. (2004). Glutamate as a therapeutic target in psychiatric disorders. Mol. Psychiatry 9, 984-997.

Johansson, S., Halleland, H., Halmoy, A., Jacobsen, K. K., Landaas, E. T., Dramsdahl, M., Fasmer, O. B., Bergsholm, P., Lundervold, A. J., Gillberg, C., Hugdahl, K., Knappskog, P. M., and Haavik, J. (2008). Genetic analyses of dopamine related genes in adult ADHD patients suggest an association with the DRD5microsatellite repeat, but not with DRD4 or SLC6A3 VNTRs. Am. J. Med. Genet. B Neuropsychiatr. Genet. 147B, 1470-1475.

Karaszewski, B., Thomas, R. G., Chappell, F. M., Armitage, P. A., Carpenter, T. K., Lymer, G. K., Dennis, M. S., Marshall, I., and Wardlaw, J. M. (2010). Brain choline concentration. Early quantitative marker of ischemia and infarct expansion? Neurology 75, 850-856.

Kaufman, J., Birmaher, B., Brent, D., Rao, U., Flynn, C., Moreci, P., Williamson, D., and Ryan, N. (1997). Schedule for affective disorders and schizophrenia for schoolage children-present and lifetime version (K-SADS-PL): initial reliability and validity data. J. Am. Acad. Child Adolesc. Psychiatry 36, 980-988.

Kessler, R. C., Adler, L., Ames, M., Demler, O., Faraone, S., Hiripi, E., Howes, M. J., Jin, R., Secnik, K., Spencer, T., Ustun, T. B., and Walters, E. E. (2005). The World Health Organization adult ADHD self-report scale (ASRS): a short screening scale for use in the general population. Psychol. Med. 35, 245-256.
Kronenberg, G., Ende, G., Alm, B. Deuschle, M., Heuser, I., and Colla, M. (2008). Increased NAA and reduced choline levels in the anterior cingulum following chronic methylphenidate. A spectroscopic test-retest study in adult ADHD. Eur. Arch. Psychiatry Clin. Neurosci. 258, 446-450.

Krystal, J. H., Mathew, S. J., D'souza, D. C., Garakani, A., Gunduz-Bruce, H., and Charney, D. S. (2010) Potential psychiatric applications of metabotropic glutamate receptor agonists and antagonists. CNS Drugs 24, 669-693.

Lesage, A., and Steckler, T. (2010). Metabotropic glutamate mGlul receptor stimulation and blockade: therapeutic opportunities in psychiatric illness. Eur. J. Pharmacol. 639, 2-16.

Ludolph, A. G., Udvardi, P. T., Schaz, U., Henes, C., Adolph, O., Weigt, H. U., Fegert, J. M., Boeckers, T. M., and Fohr, K. J. (2010). Atomoxetine acts as an NMDA receptor blocker in clinically relevant concentrations. Br. J. Pharmacol. 160, 283-291.

O'neill, M. J., and Dix, S. (2007). AMPA receptor potentiators as cognitive enhancers. IDrugs 10, 185-192.

Parsons, C. G., Danysz, W., and Zieglgansberger, W. (2005). Excitatory amino acid neurotransmission. Handb. Exp. Pharmacol. 169, 249-303.

Perlov, E., Philipsen, A., Hesslinger, B., Buechert, M., Ahrendts, J., Feige, B., Bubl, E., Hennig, J., Ebert, D., and Tebartz Van Elst, L. (2007). Reduced cingulate glutamate/glutamine-tocreatine ratios in adult patients with attention deficit/hyperactivity disorder - a magnet resonance spectroscopy study. J. Psychiatr. Res. 41 , 934-941.

Perlov, E., Philipsen, A., Matthies, S., Drieling, T., Maier, S., Bubl, E., Hesslinger, B., Buechert, M., Henning, J., Ebert, D., and Tebartz Van Elst, L. (2009). Spectroscopic findings in attentiondeficit/hyperactivity disorder: review and meta-analysis. World J. Biol. Psychiatry 10, 355-365.

Perlov, E., Tebarzt Van Elst, L., Buechert, M., Maier, S., Matthies, S., Ebert, D., Hesslinger, B., and Philipsen, A. (2010). H(1)-MRspectroscopy of cerebellum in adult attention deficit/hyperactivity disorder. J. Psychiatr. Res. 44, 938-943.

Polanczyk, G., De Lima, M. S., Horta, B. L., Biederman, J., and Rohde, L. A. (2007). The worldwide prevalence of ADHD: a systematic review and metaregression analysis. Am. J. Psychiatry 164, 942-948.
Posner, M. I., and Rothbart, M. K. (2007). Research on attention networks as a model for the integration of psychological science. Annu. Rev. Psychol. 58, 1-23.

Provencher, S. W. (1993). Estimation of metabolite concentrations from localized in vivo proton NMR spectra. Magn. Reson. Med. 30, 672-679.

Provencher, S. W. (2001). Automatic quantitation of localized in vivo $1 \mathrm{H}$ spectra with LCModel. NMR. Biomed. 14, 260-264.

Provencher, S. W. (2011). LCModel and LCMgui User's Manual. Available at: http://s-provencher.com/pages/lc model.shtml

Rusch, N., Boeker, M., Buchert, M., Glauche, V., Bohrmann, C., Ebert, D., Lieb, K., Hennig, J., and Tebartz Van Elst, L. (2010). Neurochemical alterations in women with borderline personality disorder and comorbid attention-deficit hyperactivity disorder. World J. Biol. Psychiatry 11, 372-381.

Saunders, D. E., Howe, F. A., Van Den Boogaart, A., Griffiths, J. R., and Brown, M. M. (1999). Aging of the adult human brain: in vivo quantitation of metabolite content with proton magnetic resonance spectroscopy. J. Magn. Reson. Imaging 9, 711-716.

Schubert, F., Gallinat, J., Seifert, F., and Rinneberg, H. (2004). Glutamate concentrations in human brain using single voxel proton magnetic resonance spectroscopy at 3 Tesla. Neuroimage 21, 1762-1771.

Shaw, P., Eckstrand, K., Sharp, W., Blumenthal, J., Lerch, J. P., Greenstein, D., Clasen, L., Evans, A., Giedd, J., and Rapoport, J. L. (2007). Attention-deficit/hyperactivity disorder is characterized by a delay in cortical maturation. Proc. Natl. Acad. Sci. U.S.A. 104, 19649-19654.

Solanto, M. V. (1998). Neuropsychopharmacological mechanisms of stimulant drug action in attentiondeficit hyperactivity disorder: a review and integration. Behav. Brain Res. 94, 127-152.

Sonuga-Barke, E. J., Wiersema, J. R., Van Der Meere, J. J., and Roeyers, H. (2010). Context-dependent dynamic processes in attention deficit/hyperactivity disorder: differentiating common and unique effects of state regulation deficits and delay aversion. Neuropsychol. Rev. 20, 86-102.

Staller, J. A., and Faraone, S. V. (2007). Targeting the dopamine system in the treatment of attentiondeficit/hyperactivity disorder. Expert Rev. Neurother. 7, 351-362.

Van Wageningen, H., Jorgensen, $H$. A., Specht, K., Eichele, T., and 
Hugdahl, K. (2009). The effects of the glutamate antagonist memantine on brain activation to an auditory perception task. Hum. Brain Mapp. 30, 3616-3624.

Van Wageningen, H., Jorgensen, $H$. A., Specht, K., and Hugdahl, K. (2010). A 1H-MR spectroscopy study of changes in glutamate and glutamine (Glx) concentrations in frontal spectra after administration of memantine. Cereb. Cortex 20, 798-803.

Vogt, B. A. (2009). Cingulate Neurobiology and Disease. Oxford: Oxford University Press.
Willcutt, E. G. E. G. G. (2005). Validity of the executive function theory of attention-deficit/hyperactivity disorder: a meta-analytic review. Biol. Psychiatry 57, 1336-1346.

Yang, J. W., Shih, H. C., and Shyu, B. C. (2006). Intracortical circuits in rat anterior cingulate cortex are activated by nociceptive inputs mediated by medial thalamus. J. Neurophysiol. 96, 3409-3422.

Yerli, H., Agildere, A. M., Ozen, O., Geyik, E., Atalay, B., and Elhan, A. H. (2007). Evaluation of cerebral glioma grade by using normal side creatine as an internal reference in multi-voxel 1H-MR spectroscopy.

Diagn. Interv. Radiol. 13, 3-9.

Conflict of Interest Statement: The authors declare that the research was conducted in the absence of any commercial or financial relationships that could be construed as a potential conflict of interest.

Received: 01 June 2011; accepted: 03 November 2011; published online: 23 November 2011.

Citation: Dramsdahl $M$, Ersland L, Plessen KJ, Haavik J, Hugdahl K and Specht $K$ (2011) Adults with attention-deficit/hyperactivity disorder a brain magnetic resonance spectroscopy study. Front. Psychiatry 2:65. doi: 10.3389/fpsyt.2011.00065

This article was submitted to Frontiers in Neuropsychiatric Imaging and Stimulation, a specialty of Frontiers in Psychiatry. Copyright (c) 2011 Dramsdahl, Ersland, Plessen, Haavik, Hugdahl and Specht. This is an open-access article subject to a non-exclusive license between the authors and Frontiers Media SA, which permits use, distribution and reproduction in other forums, provided the original authors and source are credited and other Frontiers conditions are complied with. 


\section{APPENDIX}

Table A1 | Independent $t$-tests of the ADHD group ( $n=29)$ with glutamate/creatine ratio left side as dependent variable, and comorbidity and medication, respectively, as grouping variables.

\begin{tabular}{|c|c|c|c|c|}
\hline & Glu/Cre left & $t$-value & df & $\boldsymbol{p}$ \\
\hline Mean - Comorb. Yes $(n=16)$ & 1.548 & 2.167 & 27 & $0.039 *$ \\
\hline Mean - Comorb. No $(n=13)$ & 1.419 & & & \\
\hline Mean - Medic. Yes $(n=16)$ & 1.469 & -0.753 & 27 & 0.458 \\
\hline Mean - Medic. No $(n=13)$ & 1.517 & & & \\
\hline
\end{tabular}

Table A2 | Main effects of general linear model including glutamate/creatine ratios at left side and right side, respectively, as dependent variables, group (ADHD, control) as categorical predictor, and sex (man, woman), handedness (left, right), age, and IQ as covariates.

\begin{tabular}{|c|c|c|c|c|c|c|c|c|c|c|}
\hline & \multicolumn{5}{|c|}{ Glu/Cre left } & \multicolumn{5}{|c|}{ Glu/Cre right } \\
\hline & SS & df & MS & $\boldsymbol{F}$ & $p$ & sS & df & MS & $\boldsymbol{F}$ & $p$ \\
\hline Group & 0.150 & 1 & 0.150 & 7.469 & $0.008^{*}$ & 0.085 & 1 & 0.085 & 3.279 & 0.075 \\
\hline Sex & 0.002 & 1 & 0.002 & 0.093 & 0.761 & 0.022 & 1 & 0.022 & 0.845 & 0.362 \\
\hline Age & 0.165 & 1 & 0.165 & 8.215 & $0.006^{*}$ & 0.085 & 1 & 0.085 & 3.279 & 0.075 \\
\hline 10 & 0.153 & 1 & 0.153 & 7.602 & $0.008^{*}$ & 0.097 & 1 & 0.097 & 3.737 & 0.058 \\
\hline Handedness & 0.091 & 1 & 0.091 & 4.523 & $0.038 *$ & 0.029 & 1 & 0.029 & 1.122 & 0.294 \\
\hline
\end{tabular}

